\title{
Patient Discomfort with Provocative Testing: Is it Worth the Diagnostic Value?
}

\author{
*Scott Huff \\ College of Medicine, University of Toledo Medical Center, USA
}

Submission: October 31, 2017; Published: November 13, 2017

*Corresponding author: Scott Huff, College of Medicine, University of Toledo Medical Center, Toledo, OH, USA, Tel: (517) 672-1433;

Email: Scott.Huff@rockets.utoledo.edu

\section{Opinion}

With a multitude of factors contributing to the high cost of medical care in the United States, most agencies are looking for ways to save money. From the perspective of insurance companies one obvious avenue is to avoid paying for unnecessary tests. Unnecessary tests are those that are conducted on a patient that will not impact their medical care in any meaningful way. For example, if a doctor suspects an ACL tear in a patient, ordering a knee X-ray, CT scan, and MRI would constitute waste. Why? The ACL is a ligament and a tear would be considered soft-tissue damage. MRI scans are great for imaging soft-tissue damage; CT scans and X-rays not as informative. The latter tests have great use in diagnosing bone fractures and damage, but limited ability to visualize soft-tissue. Understandably, the insurance companies would not want to pay for the CT scan in this situation. However, is it right for them to push back against covering the patient's MRI scan as well?

The answer is that it most likely depends on the individual patient's situation and the physician's motivation for ordering the MRI. In an ideal world, every diagnostic test would serve the purpose of benefiting the patient. In reality, medicine is practiced in a time-constrained and resource-stressed setting within the context of a litigious society. How does this translate into practice? First, with less time to discuss symptoms, examine a patient, and construct a list of possible diagnosis, physicians may be tempted to compensate by ordering a barrage of tests, hoping some sort of explanation will manifest itself in the laboratory tests or imaging. This approach is often considered lazy medical practice and can reflect upon the provider, but certainly also is a product of the current medical environment. An additional concern always on a physician's mind is the possibility of future litigation.

We live in a society that is happy to settle disputes, especially medically related ones, by going to court. If a test should have been ordered and was not, that physician is in a vulnerable position should that patient have a poor outcome. This is why in a doctor's mind, it is often better to error on the side of practicing defensive medicine i.e. ordering unnecessary tests. The 75-yearold lady who fell off her chair landing on her buttocks, whom didn't hit her head, and has no neurological symptoms to speak of, probably doesn't have a brain bleed, but if we get a head CT we can be $100 \%$ sure.

Reasonably, insurance companies prefer not to pay for unnecessary testing. They can combat this in several ways. One means is to simply refuse to pay for a test. A patient with only mild abdominal pain does not need a whole-body MRI scan, at least not initially. Another method employed by insurance companies is to require that a proper history and physical has been completed and documented. In other words, ensuring the doctor has done his homework on a patient and isn't being lazy or simply grasping for any positive diagnostic test to pursue. Roughly speaking, doctors are required to document exactly what the patient's complaints and symptoms are, as well as all the information that can be gleaned from physically examining the patient, before more expensive and/or invasive tests are completed. Many of the physical exam tests that are required in the documentation by insurance companies fall under the category of provocative tests. These types are tests involve a certain maneuver that is meant to exacerbate the patient's symptoms, typically pain. Generally, a test is considered positive if the patient's pain is acutely worsened during the maneuver.

A common sports injury is a meniscal tear of the knee. The meniscus acts as a sort of cushion between the femur and tibia, dispersing weight and decreasing friction during movement. Like an ACL tear, the meniscus is a soft-tissue injury, and as such, MRI scans are extremely useful in confirming the diagnosis. MRIs also aid in planning if a surgical intervention is required. However, many insurance companies require specific documentation of a positive provocative McMurray test before granting the patient an MRI. The McMurray test involves placing stress on either the medial or lateral meniscus while the knee is 
flexed, and then maintaining the stress as the knee is extended. An agreed upon definition of a positive result differs, but the test is generally considered positive if the patient experiences pain or pain plus clicking of the knee. Unfortunately, these findings are relatively inconsistent.

Specifically regarding meniscal pathology, a great deal of information can first be obtained from the patient's history. Complaints of their knee "locking" or "clicking" are considered to be good indicators of meniscal pathology, and hence raise a physician's concern about a possible meniscal tear. The physical exam findings tend to be more equivocal. Joint line tenderness and effusion may be present. Provocative tests include the Apley compression test, Thessaly test, and McMurray Test. Insurance companies tend to require a positive McMurray before approving an MRI. Traditionally a good diagnostic test should either nearly always be positive when pathology is present, or negative when the pathology is absent. This is referred to as sensitivity and specificity, respectively. The McMurray test is generally a nonsensative test, but with moderately high specificity.

One study found the sensitivity and specificity of the McMurray test to be $58.5 \%$ and $93.4 \%$ respectively [1]. This means it was only positive in $58.5 \%$ of the patients that were eventually found to have a definite meniscal tear by knee arthroscopy at a later time. In practice this implies that if a patient truly has a meniscal tear, they have slightly better than a coin's flip chance of being approved for an MRI to further evaluate the tear. However, with a positive result they can be fairly certain (about $93.4 \%$ certain) that their symptoms are due to a meniscal tear and not arthritis or some other pathology. Consequently, insurance companies requiring a documented positive McMurray test restricts nearly half the patients with meniscal tears from progressing through the diagnostic stages and delays their eventual treatment. Another recent study found that even the most experienced orthopedic surgeons performing the McMurray demonstrated a sensitivity and specificity of $34.3 \%$ and $86.4 \%$ respectively [2].

Beyond these obvious problems, there exists the issue of patient comfort. Provocative tests are aptly named; they provoke the patient's pain. These are not enjoyable. Medicine accepts some short-term harm to a patient in exchange for expected long-term improvement. For example, the entire field of surgery involves causing some degree of tissue damage, but for predictable improvement in a patient's overall well-being. Never-the-less, the McMurray test does not seem to fall into this category. Requiring a positive McMurray test either means patients experience short-term pain and may be approved for an MRI, or were not bothered acutely, but are now unable to obtain an MRI and experience delay in their treatment.

Extrapolating this to provocative testing in general, it seems reasonable that insurance companies should only require provocative testing if, and only if, a positive or negative test will meaningfully change the patient management. In cases where historical details elicited from the patient raise the suspicion for a specific underlying pathology to such a degree that further imaging or tests will be ordered by the physician regardless of the exam findings, provocative testing should be forgone. In other words, if your story is so consistent with a meniscal tear, that an MRI is necessary for further work-up regardless of the result of provocative testing, the provocative tests should simply not be done. Patient comfort should be a priority when possible. For this to occur, trust and decision-making power need to be placed into the hands of the provider by the insurance companies.

How can this improve moving forward? Everyone involved in the health-care arena has a role, including patients. Patients should begin by advocating for themselves. If an insurance company is trying to deny a test you and your physician feel is medically necessary, fight back. Demand to receive the care that you need. Don't hesitate to contact your physician to let them aid you in your battle. I guarantee any doctor would rather help you receive your diagnostic testing, than meet with you in clinic twoweeks later to find that he/she has no more information to work with than at the end of your last visit.

Physicians also need to put in adequate ground work when seeing patients. A proper history and physical should be obtained, and adequate consideration of potential etiologies also performed. Testing should be ordered to navigate through a differential diagnosis, not to generate a differential in the first place. And only tests with specific results that will impact the patient care should be ordered. If a test result will have no impact on the care plan, then it shouldn't be ordered. If physicians expect insurance companies to trust their judgment, physicians must also be accountable.

Finally, insurance companies should conduct adequate research into the diagnostic value of specific historical and exam findings. Physical exam tests with poor specificity should never be a required documentation for approval of additional testing. This is especially true for provocative tests where patient discomfort/pain is actively being elicited. Patient comfort is a variable that should not be ignored when developing criteria for approval of further care. Generally, testing meant to elicit pain in the patient should have significant diagnostic value or should otherwise be avoided.

\section{References}

1. Corea JR, M Moussa, al Othman A (1994) McMurray's test tested. Knee Surg Sports Traumatol Arthrosc 2(2): 70-72.

2. Galli M, V Ciriello, A Menghi, AG Aulisa, A Rabini, et al. (2013) Joint line tenderness and McMurray tests for the detection of meniscal lesions: what is their real diagnostic value? Arch Phys Med Rehabil 94(6): $1126-1131$. 
This work is licensed under Creative Commons Attribution 4.0 License

DOI: 10.19080/OROAJ.2017.09.555754
Your next submission with Juniper Publishers will reach you the below assets

- Quality Editorial service

- Swift Peer Review

- Reprints availability

- E-prints Service

- Manuscript Podcast for convenient understanding

- Global attainment for your research

- Manuscript accessibility in different formats ( Pdf, E-pub, Full Text, Audio)

- Unceasing customer service

Track the below URL for one-step submission https://juniperpublishers.com/online-submission.php 